\title{
A Review on the Use of Technology to Develop Literacy
}

\author{
Restyandito, Alan H. S. Chan, and Fransisca E. Lestariningsih
}

\begin{abstract}
Literacy has been accepted by the United Nations as one of the human rights. However, millions of people around the world are still illiterate. Technology, therefore, is believed to be able to improve the process of learning. This paper aims at reviewing some literatures concerning the issue that technology is now widely used in education as an instructional tool to enhance literacy. There are six important findings presented in this paper, i.e. technology does not need to be sophisticated; by using technology, the students' motivation in learning upwards; the materials should be locally suitable; technology should be used as a complement and not the sole mean to teach literacy; technology can facilitate active learning, but at the same time it can distract the students; and technology can create a literacy-conducive environment.
\end{abstract}

Index Terms-Instructional technology, literacy, education, computer assisted learning, e-Learning.

\section{INTRODUCTION}

UNESCO defined literacy as "the ability to read and write with understanding a short simple sentence about one's daily life" (cited from Dwyer [1]). This definition is considered too simplistic since it divides between those who are literates and illiterates, while in reality there are various levels of proficiency. Another definition of literacy is taken from the International Adult Literacy Survey (IALS) that sees literacy in terms of a mode of adult behavior, namely using printed and written information to function in society, to achieve one's goals and to develop one's knowledge and potential. Additionally, there are three domains of literacy skills; they are process literacy, document literacy, and quantitative literacy. The first domain relates to knowledge and skill needed to understand and use information from texts. Whereas the second domain relates to knowledge and skill needed to locate and use information contained in various formats; the last domain concerns with knowledge and skill needed to apply arithmetic operations [2]. Moreover, Murray et al. [2], identifies five levels of functional literacy. The lowest is the people with very poor literacy skills; they have some alphabetic knowledge but cannot use it in a functional manner. Level 2 indicates persons who can only deal with simple, short, and clear lay out text material. Those belong to level 3 have the suitable minimum skill for coping with the demands of everyday life and work in complex literate society. This level requires the ability to integrate several sources of information and solve more complex textual

Manuscript received April 25, 2013; revised June 30, 2013.

Restyandito and Alan Hoi-Shou Chan are with the Department of Systems Eng. And Engineering Mgt., City University of Hong Kong, HKSAR (e-mail rrestyand2@mslive.cityu.edu.hk, alan.chan@cityu.edu.hk).

Fransisca Endang Lestarinimgsih is with the Department of Information Technology, Duta Wacana Christian University, Indonesia (e-mail: endang@ukdw.ac.id). problems [3]. People who are able to demonstrate command of higher-order information processing skills are considered as levels 4 and 5 .

The year of 2003 to 2012 has been declared as the United Nations Literacy Decade [4], but currently there are still 775 million illiterate adults of which almost three-quarters of them are found in only ten countries (in descending order: India, China, Pakistan, Bangladesh, Nigeria, Ethiopia, Egypt, Brazil, Indonesia and the Democratic Republic of the Congo) [5]. The unequal distribution among the world's population is contrary to the fact that literacy is one of the human rights [6]. Therefore, the availability of technology, which has become accessible and affordable, can be used to improve the process of learning. The following literature review will look at various technologies available, and how they can be applied to develop literacy.

\section{INSTRUCTIONAL TECHNOLOGY}

New communication technologies seem to extend titillating possibilities to overcome learning barriers, such as cost, motivation, human resources and access. Hence technology has been used more and more as an instructional tool. Many people refer instructional technology as a section of educational technology, but the use of these two expressions has altered. As Richey [7] points out that "Educational Technology is the study and ethical practice of facilitating learning and improving performance by creating, using and managing appropriate technological processes and resources", educational technology focuses on the process of developing human capability while instructional technology hubs of the process of learning and instruction using technology.

Another expression which is commonly misunderstood with instructional technology is instructional design. Smith and Ragan [8] define instructional design as "a systematic and reflective process of translating principles of learning and instruction into plans for instructional materials, activities, information resources, and evaluation". Therefore, it can be concluded that instructional technology falls within educational technology. Likewise, instructional design falls within instructional technology. Another important term in discussing instructional technology is instructional media. Instructional media is the "way the content and methods will be delivered" [9].

Additionally, Richey and Seels (as cited in Moseley [10]) propose a model consisting of five domains, which contribute to the practice of instructional technology. Those are the design, development, utilization, management and evaluation. They depict instructional technology not simply as individual employment of given technology in a teaching environment, but rather defining instructional technology as a systematic 
process of curriculum design and delivery. This model is often used in the field to describe a system approach to the design, delivery and assessment of instructional [11]. Furthermore, Coulter [12] proposes a conceptual model of factors contributing to the utilization of instructional technology as the latent variable. They are knowledge and innovation of instructional technology, perceived institutional infrastructure, instructional experience in an institutional and barriers to use of instructional technology.

\section{DISCUSSION}

There are many ways that ICT (Information and Communication Technology) can be used to enhance literacy education, especially in the process of learning. The use of ICT can give an advantage of multimodality [13], combine pictures, texts, and sounds to stimulate more senses on human cognitive, and make the learning process more effective. Technology also enables people to raise access to literacy education and to create a literacy-conducive environment.

Therefore, ICT is employed as an effective tool to obtain literacy skills. For example, the use of radio to supplement a printed course material in India has been able to make the lesson more lively and interesting. Furthermore, the use of visual stimuli (printed material) coincided with audio stimuli (radio program) has been proven to be more fruitful in enhancing the skills of vocabulary and sentence construction [14]. It can also assist information processing and memory [15]. Other technologies, such as television and video can deliver the combination of words, images and audio in the form of animation to improve reading comprehension and escalate literacy learning. These technologies can deliver learning materials in an entertaining way, make it more compelling thus motivate the audience to engage in the learning process, stimulating discussion and critical thinking.

In a study conducted by Darter et al. [16], they explain that the use of computer assisted instruction (CAI), such as computer and multimedia programs can improve the uptake of literacy skills. They argue that "Immediate feedback reinforces correct responses or points out errors needing correction. These advantages are applied to the teaching of reading and offer a multitude of possibilities for assisting students in optimum reading development.", hence learners of literacy can proceed more quickly and effectively. Thus, the use of multimedia can satisfy the principles of interactive learning, such as situated learning, practice and feedback, learning from mistakes, and learning by doing. Darter et al. [16] also point out that CAI is very effective with all age groups. Their research dealt with various ages and varied from the intellectually handicapped to the gifted and talented. Another study Iqbal and Hammermuller [17] present the benefit of 3D technologies for adult basic education. CAI does indeed make a contribution to the learning of each particular age or ability group.

As discussed previously, the use of CAI provides an interactive learning experience, text manipulation, as well as trial and error. Since computer programs enable the users to learn and work independently without any tutor, they can learn anytime and anywhere based on their preferences.
These advantages are not available through other technologies like radio and television. In addition, computers can be fun to use, especially for people who have never used them before, thereby encourage users to continue learning and thus accelerate the retention of literacy students, as found in literacy education programs in Egypt [18].

Other technology is the mobile phone. Some studies have revealed the effectiveness of using mobile phones in empowering the illiterate people [19]-[22]. Aderinoye [19] demonstrates the use of mobile phones as one approach to improve the literacy rate among Nigeria's nomadic population by implementing a mobile learning system. A similar study was conducted by Sampangi et al. [20] in India. The adoption of mobile learning has elevated the capabilities of the users and hence assisted the elaboration of knowledge in the society. Banks [21] has managed to create a smart phone interface, enabling illiterate users to share ideas and vital information about farming and agriculture. While, Raza et al. [22] explore how telephone-based services might be mass adopted by low-literate users in Pakistan, by using fun and interesting speech-based services. These studies have illustrated that mobile devices have the capability to present novel innovations in the area of learning and education [23]. The advance development of mobile technology also brings through some advantages like that of a computer. Kumar et al. [24] explore the use of two speech recognition-enabled mobile games to assist children in rural India to read and understand words. They found that the use of such technology could increase the process training, as it enabled the users to be more active (productive training) rather than merely receptive vocabulary training. Trinder et al. [25] bring out some advantages of using mobile device in educational context, such as the immediate readiness of the device anywhere and anytime where the use of computer or laptop is not useful, hence users can take advantage of a few moments' useful studying time. Furthermore, Trinder et al. [25] also highlight that the ability of exchanging data between mobile devices will encourage communication and collaboration between learners.

The use of ICT can also raise access to literacy education. Social, political, cultural, and geographic factors can hinder someone to access literacy education. ICT, therefore, can help overcome these obstacles, for example, a course delivered via radio/television program and through the internet can be accessed by anybody regardless their social status, cultural background or geographic locations [26], [27] as well as gender issues [28].

Lastly, the use of ICT can create a literacy-conducive environment. The penetration of technology in all aspect of our daily life is a good tool to promote favorable literacy environment, thus help us to make written information part of our daily life. A television broadcasting program with text and images is an example of how ICT can bring written information into everyday life. Text message on a mobile phone is another example of how technology can improve the reading skills of the users as they read and send messages. The internet with vast resource of information provides written text that can be accessed by anyone, thus can cultivate reading practice.

Some common issues faced when using ICT in literacy 
education are related to the users/learners themselves, the technology being used and the support from the government. From the user side, the most important issue to deal with is the lack of learners' motivation. Sammie [18] points out that "for literacy programs to be effective it is therefore important that participants understand how literacy can be beneficial to them. As found in the Egypt study, learners, who understand the relevance of literacy for their lives tend to be more enthusiastic about investing their time and effort in learning to read and write". Funding and sustainability are other issues Many of the programs and studies mentioned in this review were initiated by a Non-Government Organization (NGO). Even though some of the programs may be successful, they might not be sustainable since most NGO's projects rely on intermittent funding [18]. These issues can be solved if the government has enough policies for the use of ICT in literacy education. In some countries which lack of trained educators, the governments should have strong commitment to provide human resources needed to maximize the success of the literacy education. A good policy is supposed to be made to ensure enough attention paid to the quality of the literacy education. Infrastructure also play an important role in the success of the use of ICT in the literacy education, but in many developing countries, problems, such as lack of reliable electricity supply and low bandwidth are often encountered. Gulati [29] points out that there remain high percentages of marginalized people because they do not have access to adequate resources, therefore people from lower social classes and rural areas remain deprived from gaining access to education opportunities.

Other issues need to be addressed is the usability issue. As Kukulska-Hulme [30] stated "Good usability essentially means that learning can proceed without obstacles and might even be enhanced by the availability of certain features." It is a challenge to design a CAI interface that can be understood by an illiterate user. Some of the things need to be considered are interaction style (for example, speech recognition and graphical interface) and design approach (for example, information structure and metaphors used). In addition, a designer must also take into account the physical attributes of mobile devices, such as devices and screen size, software and hardware specification.

\section{SUMMARY OF FINDINGS}

In conclusion, there are some lessons that can be learned from this comprehensive review regarding the use of ICT to develop literacy.

- The fruitful experiences of many developing countries such as India, Brazil and Pakistan [14], [26], [27] in delivering literacy education using radio and television have depicted that technology does not need to be high-tech to be useful. In deploying literacy education program, we should consider the current availability of ICT before exploring higher technology alternatives.

- Some studies explain an increase of interest and motivation of learners when they determine the subject matter [27], [13]. Therefore we ought to engage the learners and understand the need of learners. To sustain the program and develop favorable environment, the community must be encouraged to participate.

- Materials should be locally suitable, using relevant language, content and images that are fitted to the cultural setting.

- Even though ICT can enhance and compliment the learning experience, teaching and learning are social and socializing activities [13]. Therefore, technology should be used as a complement and not the sole mean to teach literacy.

- Technology can facilitate active learning, but at the same time it can distract students from learning [31]. Learners using the internet to access online course can easily open another site that is not related to their learning materials, like wise they can switch channels on television to watch something more interesting in other channels. Another example is the extensive use of mobile phones to chat with friends and families.

Technology can create a literacy-conducive environment. The appealing daily applications provided by various technologies, such as television with subtitles and text messages for easy communication can encourage the development of reading skills. Since technologies provide accessible written materials, they promote the development of literacy skills.

\section{ACKNOWLEDGMENT}

The first author would like to thank the Directorate General of Higher Education of Indonesia for supporting his study at City University of Hong Kong.

\section{REFERENCES}

[1] C. A. Dwyer. (April 2, 2011). Developing an energy literacy curriculum in support of sustainability. [Online]. Available: http://ssrn.com/abstract=1801463

[2] T. Murray, L. Jenkins, and I. S. Kirsch, "Adult literacy in OECD countries: Technical report on the first International Adult Literacy Survey," Dept. of Education, Office of Educational Research and Improvement, National Center for Education Statistics, Washington DC, U. S., 1998.

[3] S. S. V. Linden and A. M. Cremers, "Cognitive abilities of functionally illiterate persons relevant to ICT use," Lecture Notes in Computer Science, no. 5105, 2008, pp. 705-712

[4] UNESCO. (May 1, 2013). United Nations Literacy Decade. [Online]. Available:

http://www.unesco.org/new/en/education/themes/education-buildingblocks/literacy/un-literacy-decade/

[5] Indexmundi. (May 1, 2013). World Demographics Profile 2013 [Online]. http://www.indexmundi.com/world/demographics_profile.html

[6] P. Kim, T. Miranda, and C. Olaciregui, "Pocket school: Exploring mobile technology as a sustainable literacy education option for underserved indigenous children in Latin America," International Journal of Educational Development, vol. 28, no. 4, 2008, pp. 435-445.

[7] R. C. Richey, "Reflections on the 2008 AECT definitions of the field," Tech Trends, vol. 52, no. 1, 2008, pp. 24-25

[8] P. L. Smith and T. J. Ragan, Instructional design, New Jersey: Upper Saddle River, 1999.

[9] A. M. D. Leon, S. S. Brophy, and T. T. Newby, "Pre-Service teachers' perceptions of web-based interactive media: Three different tools one learning goal," Technology and Teacher Education Annual, vol. 20, 2009, pp.1502-1509.

[10] B. I. Moseley, "Description of instructional design framework usage," The Development of Learning Objects, 2013, pp. 2.

[11] B. R. Burnham, "Theoretical relationships between adult education and instructional technology," in Proc. the International Symposium for the Discussion of Graduate Study in Adult Education and Instructional Technology, Jackson Hole, WY, [CD], 2000, pp.49-56.

[12] B. M. Coulter, Utilization of instructional technology: Towards a conceptual model for teacher education, 2004. 
[13] I. Snyder, A. Jones, and J. L. Bianco. "Using information and communication technologies in adult literacy education: New practices, new challenges," Support Document, National Centre for Vocational Education Research (NCVER), 2005.

[14] B. Chatterjee, ICTs for basic education and literacy: Country study for India, pp. 10, 2004.

[15] P. Eggen and S. Schellenberg, "Human memory and the new science of learning," New Science of Learning, New York: Springer, 2010, pp. 79-107.

[16] C. L. Darter and L. N. Phelps, The impact of the computer on the teaching of literacy: A selected review of the literature, ed., pp. 326-836, 1990

[17] T. Iqbal, A. Tjoa, and K. Hammermüller, "Second life for illiterates: A 3D virtual world platform for Adult Basic Education," in Proc. IIWAS2010 - 12Th International Conference on Information Integration and Web-Based Applications And Services, 2010, pp. 373-380, doi:10.1145/1967486.1967545.

[18] M. A. Samie, "Using information and communications technology (ICT) in illiteracy eradication in Egypt (Reality and Aspirations)," UNESCO, Cairo, 2005, pp. 23.

[19] R. A. Aderinoye, K. O. Ojokheta, and A. A. Olojede. "Integrating mobile learning into nomadic education programmes in Nigeria: Issues and perspectives," International Review of Research in Open and Distance Learning, vol. 8, no. 2, 2007.

[20] R. R. Sampangi, V. V. Viswanath, and A. A. Ray, "Reaching the Unreached: A study on mobile learning in India," in Proc. Icel, 2010, pp. 350-357.

[21] K. Banks. (2012). Mobile learning: How smartphones help illiterate farmers in Rural India. [Online]. Available: http://newswatch.nationalgeographic.com/2012/06/05/mobile-learning -how-smartphones-help-illiterate-farmers-in-rural-india/

[22] A. A. Raza, F. U. Haq, Z. Tariq, M. Pervaiz, S. Razaq, U. Saif, and R. Rosenfeld, "Job opportunities through entertainment: Virally spread speech-based services for low-literate users," in Proc. CHI'13, 2013 , pp. 2803-2812.

[23] S. J. Kinshuk, E. Sutinen, and T. Goh. "Mobile technologies in support of distance learning," Asian Journal of Distance Education, vol. 1, no. 1, 2003, pp. 60-68

[24] A. Kumar, P. Reddy, A. Tewari, R. Agrawal, and M. Kam. "Improving literacy in developing countries using speech recognition-supported games on mobile devices," in Proc. the 2012 ACM Annual Conference on Human Factors in Computing Systems, 2012, pp. 1149-1158.

[25] J. Trinder, J. Magill, and S. Roy. "Expect the unexpected: Practicalities and problems of a PDA project," in Mobile Learning: A handbook for educators and trainers, Kukulska-Hulme and J. Traxler, eds., London: Routledge, 2005, pp. 92-98.

[26] J. Almeida, "A Brazilian study about the best educational practices in basic education giving priority to the teaching of reading which uses information and communication technologies," UNESCO, Brasilia, 2004.

[27] Z. M. Iqbal, Best Practices in ICT-Based Education in Pakistan, 2004. pp. $15-16$

[28] A. Dighe and U. V. Reddi, "Women's literacy and information and communication technologies: Lessons that experience has taught us," Commonwealth of Learning, Commonwealth Educational Media Centre for Asia, 2006.
[29] S. Gulati. "Technology-Enhanced learning in developing nations: A review," The International Review of Research in Open and Distance Learning, vol. 9, no. 1, 2008.

[30] A. K. Hulme. "Mobile usability in educational contexts: What have we learnt?" The International Review of Research in Open and Distance Learning, vol. 8, no. 2, 2007.

[31] K. Rollag and J. Billsberry, "Technology as the enabler of a new wave of active learning," Journal of Management Education, vol. 36, no. 6 , pp.743-752, 2012.

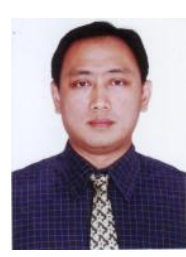

Restyandito is currently a $\mathrm{PhD}$ candidate in systems engineering and engineering management at City University of Hong Kong, Hong Kong SAR. He received the MSIS degree from School of Information Sciences, University of Pittsburgh, USA, in 1999 and B.Sc degree from Information Technology Dept. Duta Wacana Christian University, Indonesia, in 1997. He works as lecturer at Information Technology Dept., Duta Wacana Christian University since 2000. He was appointed the head of Instructional Technology and Multimedia Development Center in 2001-2005 at Duta Wacana Christian University. His research interests includes Human Computer Interaction, Human Factor, Software Engineering, Social impact of IT. He received Fellow Grant from UBCHEA as visiting scholar at Christ College, Bangalore, India in 2004, and Augustana College, Rock Island, USA, in 2006

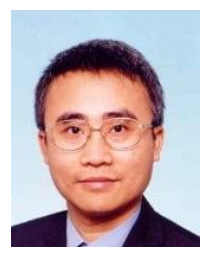

Alan H. S. Chan was born in China. He obtained his B.Sc. in industrial engineering from the Hong Kong University, Hong Kong SAR, in 1982. He then obtained his M.Phil and Ph.D in ergonomics and human factors studies from the Hong Kong University, Hong Kong SAR in 1985 and 1995 respectively. He is a senior member of Institute of Industrial Engineer, Council Member of the Asian Council on Ergonomics and Design, the Hong Kong Ergonomics Society, Fellow of the Institution of Engineering and Technology, Institution of Ergonomics and Human Factors, and Hong Kong Institution of Engineers. He is a Chartered Engineer in the UK. He has published over 120 research papers, book chapters and technical reports.

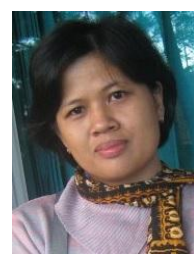

Fransisca Endang Lestariningsih was born in Jogjakarta. She received her B.Ed (bachelor of education) and M.A (master of art) from English Education Study Program of Sanata Dharma University in Yogyakarta, Indonesia, in 2000 and 2008 respectively. She also completed an online course on Learning Styles and Strategies from University of Oregon in 2010. Currently she teaches English for Informatics, at Information Technology Dept., Duta Wacana Christian University, in Yogyakarta, Indonesia. 